\title{
Ricci solitons on CR submanifolds of maximal CR dimension in complex projective space
}

\section{Mircea CRASMAREANU and LAURIAN-IOAN PIŞCORAN}

\begin{abstract}
.
We study parallel and symmetric second order tensor fields on CR submanifolds of maximal CR dimension of the complex projective space. Under some natural conditions, these tensors are scalar multiples of the metric; an example of submanifold satisfying these assumptions is the geodesic hypersphere in $P^{\frac{n+1}{2}}(\mathbb{C})$. The result is used for Ricci solitons on these CR submanifolds.
\end{abstract}

Acknowledgement. The authors are extremely indebted to two anonymous referees for their useful remarks and improvements.

\section{REFERENCES}

[1] Bejan, C. L. and Crasmareanu, M., Ricci solitons in manifolds with quasi-constant curvature, Publ. Math. Debrecen, 78 (2011), No. 1, 235-243

[2] Calin, C. and Crasmareanu, M., From the Eisenhart problem to Ricci solitons in f-Kenmotsu manifolds, Bull. Malays. Math. Sci. Soc. (2), 33 (2010), No. 3, 361-368

[3] Calin, C. and Crasmareanu, M., Eta-Ricci solitons on Hopf hypersurfaces in complex space forms, Rev. Roumaine Math. Pures Appl., 57 (2012), No. 1, 55-63

[4] Cho, J. T., Notes on contact Ricci solitons, Proc. Edinb. Math. Soc. (2), 54 (2011), No. 1, 47-53

[5] Cho, J. T. and Kimura, M., Ricci solitons and real hypersurfaces in a complex space form, Tohoku Math. J. (2), 61 (2009), No. 2, 205-212

[6] Cho, J. T. and Kimura, M., Ricci solitons of compact real hypersurfaces in Kähler manifolds, Math. Nachr., 284 (2011), No. 11-12, 1385-1393

[7] Crasmareanu, M., Parallel tensors and Ricci solitons in $N(k)$-quasi Einstein manifolds, Indian J. Pure Appl. Math., 43 (2012), No. 4, 359-369

[8] Deshmukh, S., Real hypersurfaces of a complex space form, Monatsh. Math., 166 (2012), 93-106

[9] Djoric, M. and Okumura, M., CR submanifolds of maximal CR dimension of complex projective space, Arch. Math. (Basel), 71 (1998), No. 2, 148-158

[10] Djoric, M. and Okumura, M., CR submanifolds of complex projective space, Developments in Mathematics, 19, Springer, New York, 2010

[11] Eisenhart, L. P., Symmetric tensors of the second order whose first covariant derivatives are zero, Trans. Amer. Math. Soc., 25 (1923), No. 2, 297-306

[12] Ghosh, A., Certain results of real hypersurfaces in a complex space form, Glasg. Math. J., 54 (2012), No. 1, 1-8

[13] Hamada, T., On real hypersurfaces of a complex projective space with recurrent Ricci tensor, Glasg. Math. J., 41 (1999), No. 3, 297-302

[14] Kaimakamis, G. and Panagiotidou, K., *-Ricci solitons of real hypersurfaces in non-flat complex space forms, J. Geom. Phys., 86 (2014), 408-413

[15] Levy, H., Symmetric tensors of the second order whose covariant derivatives vanish, Ann. of Math. (2), 27 (1925), No. 2, 91-98

[16] Loo, T.-H., Real hypersurfaces in a complex space form with recurrent Ricci tensor, Glasg. Math. J., 44 (2002), No. $3,547-550$

Received: 24.03.2015; In revised form: 28.12.2015; Accepted: 04.01.2016

2010 Mathematics Subject Classification. 53C40, 53C15.

Key words and phrases. Complex projective space, $C R$ submanifold of maximal $C R$ dimension, Ricci soliton.

Corresponding author: Laurian-Ioan Pişcoran; plaurian@yahoo.com 
[17] Petersen, P., Riemannian geometry. Second edition, Graduate Texts in Mathematics, 171, Springer, New York, 2006

[18] Sharma, R., Second order parallel tensor in real and complex space forms, Internat. J. Math. Math. Sci., 12 (1989), No. $4,787-790$

[19] Sharma, R., Second order parallel tensors on contact manifolds. I, Algebras Groups Geom., 7 (1990), No. 2, $145-152$

[20] Sharma, R., Second order parallel tensors on contact manifolds. II, C. R. Math. Rep. Acad. Sci. Canada, 13 (1991), No. 6, 259-264

[21] Sharma, R., On the curvature of contact metric manifolds, J. Geom., 53 (1995), No. 1-2, 179-190

[22] Sharma, R., Certain results on $K$-contact and $(k, \mu)$-contact manifolds, J. Geom., 89 (2008), 138-147

FACULTY OF MATHEMATICS

UNIVERSITY "AL. I. CUZA"

IAŞI 700506, ROMANIA

E-mail address: mcrasmeuaic.ro

Department of Mathematics AND COMPUter SCIENCE

NORTH UNIVERSITY CENTER AT BAIA MARE

TECHNICAL UNIVERSITY OF CLUJ-NAPOCA

VICTORIEI 76, 430122 BAIA MARE, ROMANIA

E-mail address: plaurian@yahoo.com 